\title{
A comparison between the Farr radioimmunoassay and a new automated fluorescence immunoassay for the detection of antibodies against double stranded DNA in serum
}

\author{
R H W M Derksen, E J E G Bast, T Strooisma, J W G Jacobs
}

Ann Rheum Dis 2002;61:1099-1 102

Objective: To compare test characteristics of the Farr radioimmunoassay and an automated fluorescence immunoassay (ELIA dsDNA test) for the diagnosis of systemic lupus erythematosus (SLE).

Methods: A cross sectional study comprising 440 samples from 440 patients, sent to the laboratory over a three month period for anti-dsDNA testing. Chart review was performed, blinded for test results, to count for each patient the number of American College of Rheumatology criteria for the classification of SLE that were fulfilled. At least four criteria were met by $248(56 \%)$ patients (SLE), one to three criteria by 77 (18\%) (lupus-like disease, LLD), and no criterion by 115 (26\%) (non-SLE/non-LLD). Results from serum samples from the non-SLE/non-LLD and SLE groups were used to calculate receiver operating characteristic curves. Results: For the Farr assay, specificities of $95 \%$ and $99 \%$ corresponded to sensitivities of $72 \%$ and $56 \%$ respectively. For the ELIA dsDNA test these levels of specificity corresponded to sensitivities of $44 \%$ and $17 \%$ respectively.

Conclusions: The Farr radioimmunoassay is superior to the ELIA dsDNA test for identifying patients with SLE.

$\mathrm{B}$ etween $60 \%$ and $80 \%$ of patients with systemic lupus erythematosus (SLE) have circulating antibodies to double stranded DNA (dsDNA) at some time during their illness. ${ }^{1}$ Their presence provides the clinician with one out of the four American College of Rheumatology (ACR) criteria necessary to classify a patient as having SLE. ${ }^{2}$ The techniques most commonly used for detection of anti-dsDNA antibodies are enzyme linked immunosorbent assay (ELISA), indirect immunofluorescence using the haemoflagellate Crithidia luciliae (CLIF), and the Farr radioimmunoassay. ${ }^{3}$ The techniques of ELISA and CLIF detect anti-dsDNA antibodies with both high or low avidity. As the Farr assay includes ammonium sulphate precipitation at high salt concentrations, a condition that dissociates dsDNA-anti-dsDNA complexes of low avidity, ${ }^{4}$ this assay detects only antibodies with high avidity. ${ }^{5}$ High avidity anti-dsDNA antibodies are more specific for SLE than those with low avidity $y^{5}$ and have high predictive value for the development of SLE if present in patients with manifestations compatible with SLE who fulfil fewer than four ACR criteria at the time of evaluation (lupus-like disease, LLD). ${ }^{6}$

Recent communications suggest that a non-radioactive automated fluorescence immunoassay (ELIA dsDNA test) has similar test characteristics to those of the Farr radioimmunoassay. ${ }^{7-9}$ This study compares both tests in a setting that mimics daily clinical practice.

\section{PATIENTS AND METHODS \\ Patient samples}

We included all 440 blood samples from 440 different patients, sent to the immunology laboratory of our hospital for anti-dsDNA testing between February and May 2001. One of us (RHWMD), blinded for test results, reviewed clinical charts and scored the number of ACR criteria ${ }^{2}$ that each patient fulfilled. Patients with four or more criteria were classified as having SLE; those with one to three criteria as having LLD. Those who met no criterion or had a positive test for antinuclear antibodies (ANA, as measured by Hep-2000 immunofluorescence) as the only criterion were classified as non-SLE/non-LLD.

\section{Anti-dsDNA antibodies}

Anti-dsDNA antibodies were determined according to the manufacturer's instructions with the Farr assay (Diagnostic Products Corporation, Los Angeles, USA) using ${ }^{125}$ I-labelled recombinant dsDNA and the ELIA ${ }^{\mathrm{TM}}$ dsDNA test (Pharmacia BV Diagnostics GmbH and Co, KG, Freiburg, Germany) that uses single polystyrene wells coated with double stranded cyclic plasmid DNA of Escherichia coli, which are automatically dispensed and processed (including instrument dilution of patient samples) in the UniCAP ${ }^{\circledast} 100^{\epsilon}$ instrument at $37^{\circ} \mathrm{C}$ (Pharmacia and Upjohn Diagnostics $\mathrm{GmbH}$ and Co, KG, Freiburg, Germany). Results were expressed in IU/ml, using $\mathrm{Wo} / 80$ as the ultimate standard. Cut off levels advised by the manufacturer are $10 \mathrm{IU} / \mathrm{ml}$ (Farr assay) and $15 \mathrm{IU} / \mathrm{ml}$ (ELIA dsDNA test). For both tests intra-assay and interassay variations were $<10 \%$.

\section{RESULTS}

\section{Patient characteristics}

One hundred and fifteen (26\%) patients (69\% women; median age 40 years) were classified as non-SLE/non-LLD, 77 (18\%) patients as LLD (86\% women; median age 35 years), and 248 (56\%) patients as SLE ( $90 \%$ women; median age 35 years; median disease duration 10 years). In the non-SLE/non-LLD group, respectively $20 \%$ and $0 \%$ of patients had a history of a positive antinuclear antibody (ANA) and anti-dsDNA test result. For the LLD and SLE groups these percentages were $70 \%$ and $98 \%$ for ANA, and $26 \%$ and $87 \%$ for anti-dsDNA. Figure 1 depicts frequencies of ACR criteria in patients with LLD

Abbreviations: ACR, American College of Rheumatology; ANA, antinuclear antibodies; CDLE, chronic discoid lupus; CLIF, Crithidia luciliae immunofluorescence; dsDNA, double stranded DNA; ELIA, fluorescence immunoassay; ELISA, enzyme linked immunosorbent assay; LLD, lupus-like disease; ROC, receiver operating curve; SLE, systemic lupus erythematosus 


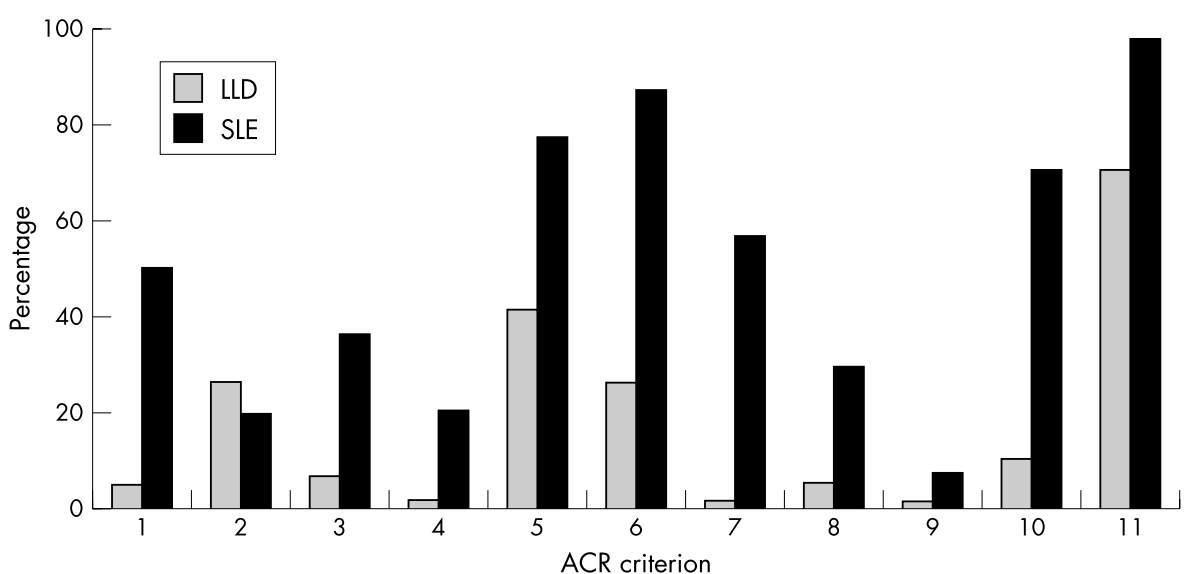

Figure 1 Prevalence of ACR criteria for the classification of systemic lupus erythematosus (SLE) in 77 patients with lupus-like disease (LLD) and 249 patients with SLE. Numbers on the $x$ axis represent individual criteria. 1, Butterfly rash; 2, chronic discoid lupus (CDLE); 3, photosensitivity; 4, oropharyngeal ulcers; 5 , arthritis of at least two joints; 6, anti-dsDNA antibodies (any assay, any time); 7, nephritis; 8, serositis; 9, psychosis and/or epilepsy; 10, haemolytic anaemia, leucocytopenia, and/or thrombocytopenia; 11, ANA.

or SLE. Patients with SLE met a median of five ACR criteria (range 4 to 10). Had the presence of anti-dsDNA antibodies not been tested for, $18 \%$ of patients with SLE would have only met three criteria.

\section{Results with the Farr and ELIA dsDNA test}

Figure 2 (panels A-C) shows results with both antidsDNA tests for all three groups of patients. We used results with samples from SLE and non-SLE/non-LLD groups to calculate receiver operating curves (ROCs) (fig 2, panel D). A specificity of $95 \%$ corresponded to a cut off point between "negative" and "positive" results of 6 and $19 \mathrm{IU} / \mathrm{ml}$ for the Farr assay and the ELIA dsDNA test, respectively. Corresponding sensitivities were $72 \%$ (Farr assay) and 44\% (ELIA dsDNA test). Specificities and sensitivities with cut off levels advised by the manufacturers ( $10 \mathrm{IU} / \mathrm{ml}$ for Farr assay; $15 \mathrm{IU} / \mathrm{ml}$ for

A

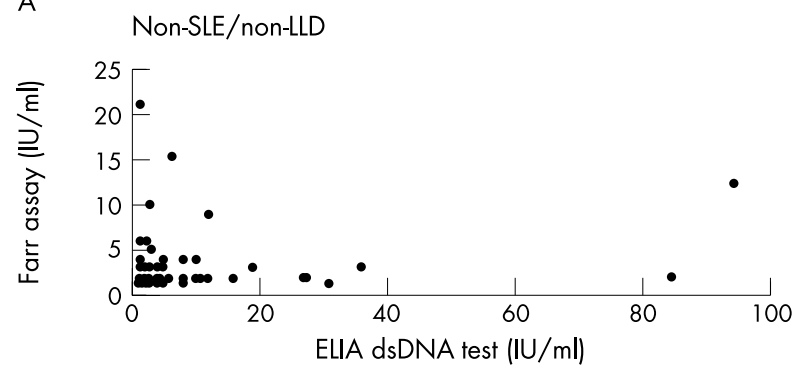

C

Systemic lupus erythematosus (SLE)

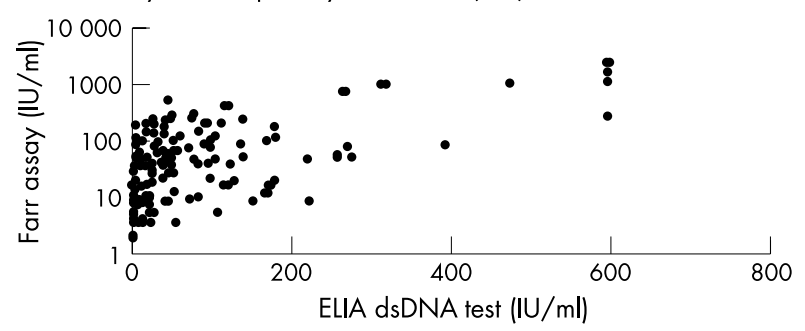

ELIA dsDNA test) were $98 \%$ and $59 \%$ for the Farr assay, and $94 \%$ and $47 \%$ for the ELIA dsDNA test, respectively. With a cut off point at $12 \mathrm{IU} / \mathrm{ml}$, the Farr assay reached a specificity of $99 \%$ (corresponding sensitivity 56\%). For the ELIA dsDNA test $99 \%$ specificity was reached with a cut off point at $84 \mathrm{IU} / \mathrm{ml}$, with a corresponding (clinically irrelevant) sensitivity of $17 \%$ (fig 2, panel D).

For a test result considered positive with values exceeding the cut off point corresponding to $95 \%$ specificity ( $\geqslant 6 \mathrm{IU} / \mathrm{ml}$ for the Farr assay and $\geqslant 19 \mathrm{IU} / \mathrm{ml}$ for the ELIA dsDNA test), 12 (10\%) samples from the non-SLE/non-LLD group, 29 (38\%) from the LLD group, and 188 (76\%) from the SLE group, were positive with at least one anti-dsDNA test. Table 1 gives details on corresponding patients from the first two groups. A positive ANA test was present in four out of seven (57\%) Farr positive and one out of six ELIA dsDNA test positive samples from

B
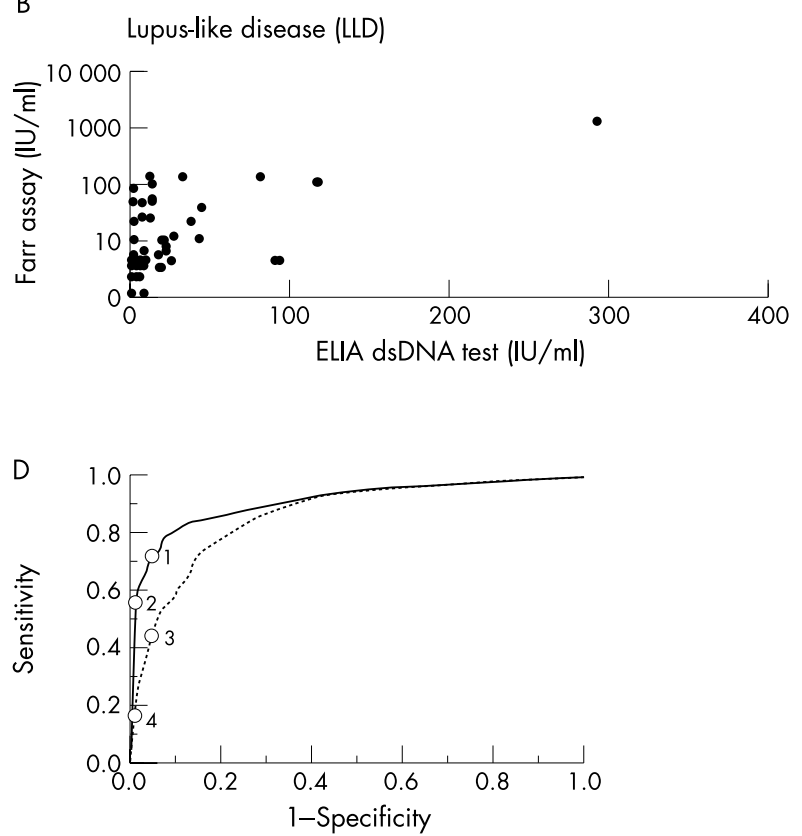

Figure 2 Results with the Farr assay and ELIA dsDNA test in IU/ml for the patients who were non-SLE/non-LLD ( $\mathrm{n}=115$, panel $A)$, patients with LLD $(n=77$, panel B), and those with SLE ( $n=248$, panel C). The results for the Farr assay are shown in panels A, B and C on the $y$ axis; the $y$ axis in panels $B$ and $C$ has a log scale. Panel D depicts the ROC curve for the Farr assay (continuous line) and ELIA dsDNA test (dotted line). Circles 1 and 2 correspond to cut off points for the Farr assay of $6 \mathrm{IU} / \mathrm{ml}$ and $12 \mathrm{lU} / \mathrm{ml}$, respectively. These cut off points result in $95 \%$ and $99 \%$ specificity, respectively. Circles 3 and 4 correspond to cut off points with the ELIA dsDNA test of $19 \mathrm{lU} / \mathrm{ml}$ and $84 \mathrm{IU} / \mathrm{ml}$, respectively. These cut off points have a specificity of $95 \%$ and $99 \%$, respectively. 
Table 1 Characteristics of patients in the non-SLE/non-LLD group $(n=12)$ and with lupus-like disease $(n=29)$ and a positive Farr assay ( $\geqslant 6 \mathrm{IU} / \mathrm{ml}$ ) and/or a positive ELIA dsDNA test ( $\geqslant 19 \mathrm{IU} / \mathrm{mll}$ ). Bold numbers with titres (IU/ml) correspond with positive test results

\begin{tabular}{|c|c|c|c|c|c|}
\hline $\begin{array}{l}\text { Patient } \\
\text { number }\end{array}$ & $\begin{array}{l}\text { Farr } \\
(I U / m l)\end{array}$ & $\begin{array}{l}\text { ELIA dsDNA test } \\
(I \mathrm{U} / \mathrm{ml})\end{array}$ & Sex & $\begin{array}{l}\text { Age } \\
\text { (years) }\end{array}$ & Clinic \\
\hline \multicolumn{6}{|c|}{ Non-SLE/non-LLD group } \\
\hline 1 & 12 & 95 & $\mathrm{~F}$ & 34 & $\begin{array}{l}\text { Raynaud, myositis, ANA positive. } \\
\text { During follow up: pericarditis }\end{array}$ \\
\hline 2 & 21 & 1 & $\mathrm{~F}$ & 79 & Chronic obstructive pulmonary disease, drug induced hepatitis, ANA negative \\
\hline 3 & 10 & 3 & $\mathrm{~F}$ & 48 & Myasthenia gravis, ANA negative \\
\hline 4 & 9 & 12 & $\mathrm{~F}$ & 52 & Sjögren's syndrome, ANA positive \\
\hline 5 & 6 & 1 & $\mathrm{~F}$ & 69 & Recurrent urinary tract infections, ANA positive \\
\hline 6 & 6 & 2 & $\mathrm{~F}$ & 38 & Polymyositis, ANA negative \\
\hline 7 & 6 & 2 & $\mathrm{~F}$ & 45 & Sjögren's syndrome, ANA positive \\
\hline 8 & 2 & 85 & M & 82 & Vocal cord paresis, myelodysplastic syndrome, ANA negative \\
\hline 9 & 3 & 36 & $\mathrm{~F}$ & 59 & Reumatoid factor positive, nodular reumatoid arthritis, ANA negative \\
\hline 10 & 1 & 31 & M & 51 & Hepatitis B related liver cirrhosis, ANA negative \\
\hline 11 & 2 & 27 & $\mathrm{~F}$ & 50 & Recent bacterial endocarditis and aortic valve replacement, ANA negative \\
\hline 12 & 3 & 19 & M & 79 & $\begin{array}{l}\text { Complex neurological picture with multisystem atrophy, idiopathic myelopathy. Prostate } \\
\text { cancer. ANA negative }\end{array}$ \\
\hline \multicolumn{6}{|r|}{ 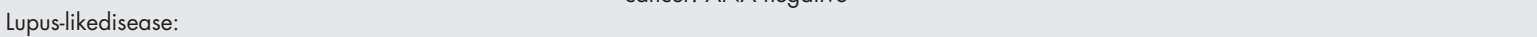 } \\
\hline 13 & 1223 & 292 & $\mathrm{~F}$ & 52 & Thrombocytopenia, arthralgia, autoimmune hepatitis, adsDNA and ANA positive. \\
\hline 14 & 132 & 33 & $\mathrm{~F}$ & 27 & Arthritis, adsDNA and ANA positive. \\
\hline 15 & 129 & 82 & $\mathrm{~F}$ & 33 & Arthritis, Siögren's syndrome, adsDNA and ANA positive. \\
\hline 16 & 105 & 117 & $\mathrm{~F}$ & 13 & Serositis, arthralgia, Raynaud, vitiligo, adsDNA and ANA positive. \\
\hline 17 & 36 & 45 & M & 46 & Thrombocytopenia, tendinitis, adsDNA and ANA positive \\
\hline 18 & 19 & 38 & $\mathrm{~F}$ & 40 & Serositis, adsDNA and ANA positive \\
\hline 19 & 11 & 28 & $\mathrm{~F}$ & 17 & Arthritis, adsDNA and ANA positive \\
\hline 20 & 10 & 42 & $\mathrm{~F}$ & 16 & Leuco- and thrombocytopenia, arthralgia, adsDNA and ANA positive. \\
\hline 21 & 9 & 21 & $\mathrm{~F}$ & 19 & Seronegative rheumatoid arthritis, ANA positive \\
\hline 22 & 7 & 24 & $\mathrm{~F}$ & 46 & Arthritis, antiphospholipid syndrome, ANA positive \\
\hline 23 & 6 & 24 & $\mathrm{~F}$ & 34 & CDLE, antiphospholipid syndrome, ANA positive \\
\hline 24 & 137 & 13 & $\mathrm{~F}$ & 22 & Arthritis, myositis, Raynaud, adsDNA and ANA positive. \\
\hline 25 & 92 & 15 & $\mathrm{~F}$ & 26 & Arthritis, adsDNA and ANA positive \\
\hline 26 & 76 & 3 & M & 7 & $\begin{array}{l}\text { Arthritis, adsDNA and ANA-positive } \\
\text { During follow up: mild haemolysis }\end{array}$ \\
\hline 27 & 53 & 14 & $\mathrm{~F}$ & 54 & Arthritis, adsDNA and ANA-positive \\
\hline 28 & 46 & 3 & $\mathrm{~F}$ & 37 & Chronic intermittent isolated microscopic haematuria, arthralgia, adsDNA and ANA-positive \\
\hline 29 & 44 & 15 & $\mathrm{~F}$ & 39 & Arthritis, antiphospholipid syndrome, adsDNA and ANA positive \\
\hline 30 & 41 & 7 & $\mathrm{~F}$ & 44 & Malar rash, arthralgia, Sjögren's syndrome, adsDNA and ANA positive \\
\hline 31 & 26 & 7 & $\mathrm{~F}$ & 56 & Serositis, arthralgia, Raynaud, adsDNA and ANA positive \\
\hline 32 & 23 & 13 & $\mathrm{~F}$ & 29 & Oral ulcers, arthralgia, adsDNA and ANA positive \\
\hline 33 & 20 & 3 & $\mathrm{~F}$ & 55 & Chronic discoid lupus, myasthenia gravis, adsDNA and ANA positive \\
\hline 34 & 19 & 2 & $\mathrm{~F}$ & 46 & Arthritis, adsDNA and ANA positive \\
\hline 35 & 10 & 2 & $\mathrm{~F}$ & 15 & Autoimmune haemolytic anaemia, adsDNA and ANA positive \\
\hline 36 & 9 & 3 & $\mathrm{~F}$ & 15 & Arthritis, Raynaud, adsDNA and ANA positive \\
\hline 37 & 6 & 9 & $\mathrm{~F}$ & 48 & Arthritis, ANA positive \\
\hline 38 & 4 & 91 & $\mathrm{~F}$ & 53 & Chronic discoid lupus, ANA negative \\
\hline 39 & 4 & 26 & M & 37 & Arthritis, ANA-positive \\
\hline 40 & 3 & 19 & $\mathrm{~F}$ & 34 & Thrombocytopenia, antiphospholipid syndrome, ANA positive \\
\hline 41 & 3 & 19 & $\mathrm{~F}$ & 38 & Arthritis, serositis, Raynaud, ANA negative \\
\hline
\end{tabular}

patients in the non-SLE/non-LLD group. In samples from patients with LLD all Farr positive samples and all but two ELIA dsDNA test positive samples were ANA positive. In samples from patients who were non-SLE/non-LLD, the titre in the Farr assay was $\leqslant 10 \mathrm{IU} / \mathrm{ml}$ in five out of six who were Farr positive and ELIA dsDNA test negative, whereas the titre in the ELIA-dsDNA test was >15 IU/ml in five Farr negative, ELIA dsDNA test positive samples. As a result, the use of cut off points advised by the manufacturer reduced the number of Farr positive samples in the non-SLE/non-LLD group to two, whereas the number of ELIA dsDNA test positive samples was unchanged. Application of cut off points advised by the manufacturers to samples from patients with LLD reduced the number of positive samples in the Farr assay from 25 to seven and did not affect the number of positive samples with the ELIA dsDNA test.

Taking $\geqslant 6 \mathrm{IU} / \mathrm{ml}$ for the Farr assay and $\geqslant 19 \mathrm{IU} / \mathrm{ml}$ for the ELIA dsDNA test as cut off points for a positive test, 77 samples (31\%) from patients with SLE were Farr positive and ELIA dsDNA test negative and seven samples (3\%) were Farr negative and ELIA dsDNA test positive. Application of the manufacturers' cut off points reduced the number of Farr positive and ELIA dsDNA test negative samples to 49 and increased the number of Farr negative and ELIA dsDNA test positive samples to 17. Overall, application of the manufacturers' cut off points decreased the number of Farr positive SLE samples from $181(73 \%)$ to $150(60 \%)$ and increased the number positive in the ELIA dsDNA test from 111 (45\%) to $118(48 \%)$.

\section{DISCUSSION}

Compared with the Farr radioimmunoassay the recently introduced ELIA dsDNA test has several advantages. The test does not use radioactive materials (no specific location in the laboratory or specialised personnel needed; no fear of radioactive irradiation for technicians and milieu), takes less time (a run takes 2.5 hours compared with seven hours with the Farr assay; "hands on" time: one hour $v$ five hours with the Farr assay) and has a similar cost per analysed sample (considering materials, technicians, and apparatus). For diagnostic purposes clinicians need a disease specific and sensitive assay. The ROC curves (fig 2 D) clearly showed that the Farr 
assay performs better than the ELIA dsDNA test. Other communications published in abstract form ${ }^{7-9}$ concluded that specificity and sensitivity are almost the same for both assays. A likely explanation for these different conclusions is a

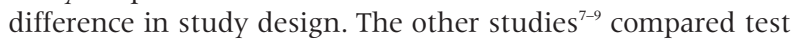
results with samples from patients with SLE with those from healthy blood donors, "control sera", patients with Sjögren's syndrome, rheumatoid arthritis, "various disorders", and patients with IgA nephritis. Our study design differs in two important aspects. Firstly, our setting mirrors daily clinical practice as we used all requests for anti-dsDNA testing that came from the clinic to the laboratory. Secondly, we divided the patients into SLE, LLD and non-SLE/non-LLD groups, blinded for the test results, and did not use the results in the LLD group for calculation of specificity and sensitivity. Identification of patients with LLD is of importance when an anti-dsDNA test is evaluated. As a patient is allowed to "collect" the required number of ACR criteria over any period, ${ }^{2}$ the result of an anti-dsDNA test cannot be classified as "incorrect" in a patient with clinical manifestations that are compatible with SLE. We consider differences in the percentage of included SLE patients with active disease a less likely explanation for the different conclusions of our study and those of others, ${ }^{7-9}$ as this difference holds for the ELIA dsDNA test and not for the Farr assay. The test characteristics with the Farr assay in our study (depending on the cut off point specificity of $95 \%$ to $72 \%$ ), were comparable with those in the other studies (specificity 96\%, sensitivity $32 \%^{7}$; specificity $>90 \%$, sensitivity $71 \%^{8}$; specificity $99 \%$, sensitivity $63 \%{ }^{9}$ ).

Almost all Farr positive samples in our study also had a positive ANA test, as expected for samples with anti-dsDNA antibodies. However, several samples that were ELIA dsDNA test positive and Farr negative were ANA negative (table 1). These findings suggest that both assays may detect different antibodies.

It should be stressed that our study was only designed to evaluate the diagnostic capacity of the Farr assay and ELIA dsDNA test. It has been shown that changes in antibody levels as measured by the Farr assay ${ }^{11}$ and ELISA or CLIF techniques $^{12}$ are related to exacerbations of disease. Further studies are needed to evaluate whether this also holds for the ELIA dsDNA test.

\section{ACKNOWLEDGEMENT}

We thank Mr T de Poorter, Pharmacia BV Diagnostics, Woerden, the Netherlands for providing the apparatus and materials for the ELIA dsDNA test.

\section{Authors' affiliations}

R H W M Derksen, J W G Jacobs, Department of Rheumatology and Clinical Immunology, University Medical Centre, PO Box 85500, 3508 GA Utrecht, The Netherlands

E J E G Bast, T Strooisma, Laboratory of Immunology, University Medical Centre, Utrecht, The Netherlands

Correspondence to: Dr R H W M Derksen, Department of Rheumatology and Clinical Immunology (FO2.127), University Medical Centre, PO Box 85500, 3508 GA Utrecht, The Netherlands:

r.h.w.m.derksen@digd.azu.nl

Accepted 7 May 2002

\section{REFERENCES}

1 Hahn BH. Antibodies to DNA. N Engl J Med 1998;338:1359-68.

2 Tan EM, Cohen AS, Fries JF, Masi AT, McShane DJ, Rothfield NF, et al. The 1982 revised criteria for the classification of systemic lupus erythematosus. Arthritis Rheum 1982;25:1271-7.

3 Egner W. The use of laboratory tests in the diagnosis of SLE. J Clin Pathol 2000;53:424-32.

4 Smeenk R, van der LG, Aarden L. Avidity of antibodies to dsDNA: comparison of IFT on Crithidia luciliae, Farr assay, and PEG assay. J Immunol 1982;128:73-8.

5 Smeenk RJ, van den Brink HG, Brinkman K, Termaat RM, Berden JH, Swaak AJ. Anti-dsDNA: choice of assay in relation to clinical value. Rheumatol Int 1991:11:101-7.

6 Swaak T, Smeenk R. Detection of anti-dsDNA as a diagnostic tool: a prospective study in 441 non-systemic lupus erythematosus patients with anti-dsDNA antibody (anti-dsDNA). Ann Rheum Dis 1985:44:245-51.

7 González H, Sánchez A, Guevara P, Navajo JA, González-Buitrago J, Papisch W. Anti-dsDNA antibodies in SLE. Clinical evaluation of an ELISA and a new enzyme immunoassay on an automated plafform, both using recombinant plasmid dsDNA [abstract]. Lupus 2001;10/suppl 1):S126.

8 Papisch W, Höpfl P, Zöllner Th. Comparison of different methods for detection of dsDNA antibodies: evaluation of a new automated fluorescence immunoassay [abstract]. Lupus 2001;10(suppl 1):S126.

9 Hermann J, Salmhofer W. A new fluorescence immunoassay as an alternative to the Farr assay for double-stranded DNA-antibody testing [abstract]. Lupus 2001;10 (suppl 1):S126.

10 ter Borg EJ, Horst G, Hummel EJ, Limburg PC, Kallenberg CG. Measurement of increases in anti-double-stranded DNA antibody levels as a predictor of disease exacerbation in systemic lupus erythematosus: a long-term, prospective study. Arthritis Rheum 1990;33:634-43.

11 Bootsma H, Spronk P, Derksen R, de Boer G, Wolters-Dicke H, Hermans $\mathrm{J}$, et al. Prevention of relapses in systemic lupus erythematosus. Lancet 1995:345:1595-9.

12 Ho A, Magder LS, Barr SG, Petri M. Decreases in anti-double-stranded DNA levels are associated with concurrent flares in patients with systemic lupus erythematosus. Arthritis Rheum 2001;44:2342-9. 